\title{
Distal Extension Removable Partial Denture with Resilient Attachment Connected to an Anterior Fixed Implant-Supported Prosthesis: A Clinical Report
}

Ricardo Alexandre Zavanelli, José Vitor Quinelli Mazaro, Adérico Santana Guilherme, Jaqueline Barbosa Magalhães Leandro de Carvalho Cardoso, Adriana Cristina Zavanelli

\begin{abstract}
Background: Considering the limited qualitative and quantitative bone in the posterior arch, this modality of prosthetic treatment could provide a positive emotional factor reestablished by immovability of the anterior fixed implant-supported segment.

Objective: This clinical report demonstrates the possibility of achieving positive results with a removable partial denture connected to an implant-supported fixed prosthesis associated to an extra resilient attachment.

Clinical significance: In cases of posterior mandibular and maxilla atrophy added to the patients desire against the bone graft, this kind of prosthetic treatment has an important place as an alternative.
\end{abstract}

Keywords: Removable partial denture, Implant-supported prosthesis, Resilient attachment.

How to cite this article: Zavanelli RA, Mazaro JVQ, Guilherme AS, Magalhães JB, de Carvalho Cardoso L, Zavanelli AC. Distal Extension Removable Partial Denture with Resilient Attachment Connected to an Anterior Fixed Implant-Supported Prosthesis: A Clinical Report. World J Dent 2012;3(1):87-90.

Source of support: Nil

Conflict of interest: None declared

\section{INTRODUCTION}

The early prosthodontic restorations with implants for an edentulous arch often involved cantilever devices, whether an extended bar-clip substructure or a screw-retained hybrid or fixed-removable prosthesis. ${ }^{1}$

The ultimate goal of an implant-retained prosthesis is to ensure that the esthetic and functional needs of the patients are met with minimal discomfort and limited complications. Esthetic restrictions, poor quality bone in a specific site, and the need for extensive bone grafting are critical considerations. ${ }^{1}$ When patients demanded more extensive use of implants for posterior quadrants, cantilever prosthesis could be considered.

Notwithstanding, disadvantages of a fixed implantsupported prosthesis with distal cantilevers could be functional and biomechanical. ${ }^{2}$ The design of the framework and the rigid connection between the framework and implants determine a transfer of bending moments to the bone-implant interface and development of shearing forces that can damage the osseointegration process. From a functional point of view, the implant-supported fixed prosthesis with distal cantilevers does not significantly improve masticatory effectiveness. ${ }^{3}$

An alternative reconstructive option that does not involve grafting and multiple surgical procedures for the patient is a bilateral removable partial denture anchored to a fixed prosthesis, supported by implants placed in the interforaminal region or in the premaxilla, with stress directors near the connection with the fixed prosthesis.

This alternative option, in addition to the esthetic and functional advantage of an overdenture, gives a decreased compression of the edentulous ridge in function and immovability of the anterior segment. This article describes the treatment of a patient with this prosthetic solution.

\section{CASE REPORT}

A 65-year-old white woman was evaluated for prosthetic treatment and her chief complaint was that her complete dentures present instable. A lack of retention and stability was confirmed during intraoral examination. Several options of prosthetic treatment were offered to the patient: New complete dentures, an implant-supported overdenture, a fixed implant-supported after guided bone regeneration to rebuild the ridge height in the posterior arch of the mandible and maxilla or a combination of a fixed implant-supported anterior prosthesis with a distal extension mandibular removable partial denture in association with an extraresilient-attachment. After reviewing the options, the patient accepted the last treatment option.

A surgical template was fabricated by duplicating the patient's complete dentures. In the surgical moment and after exposure of the alveolar ridge, four implants $(3.75 \times$ $13 \mathrm{~mm}$, Lifecore, Restore) were placed in the mandibular ridge between the mental foramen, and four implants $(3.75 \times 13 \mathrm{~mm}$, Lifecore, Restore $)$ were placed in the premaxilla, regions of remaining available bone. One week after stage 1 surgery, the patient's complete dentures were relined with resilient material (Every Soft, Myerson) to reduce the patient discomfort waiting the osseointegration period. The implant site was relieved to avoid transmucosal loading and to assist the osseointegration process. This relining procedure was repeated once a month during the 6 months of healing. ${ }^{4}$ 
After 6 months healing, the following procedure was followed (Figs 1 to 7):

1. At the second stage surgery, expose the implants and insert the healing abutments, reline the patient's dentures with the healing abutments in position.

2. After additional healing time, remove the healing abutments and place conical impression copings on the implants to make the initial impression using a custom tray. Attach the conical laboratory analogs and make the superior and inferior cast in dental stone.

3. Construct an individual tray over the initial stone cast to make the definitive impression. Place square impression copings (pick-up) on the implants and make the definitive superior and inferior impression using polieter material (Impregum, Espe). Attach the laboratory analogs, put artificial gingiva and make the definitive superior and inferior cast to improve dental stone. Replace the healing abutments and dismiss the patient.

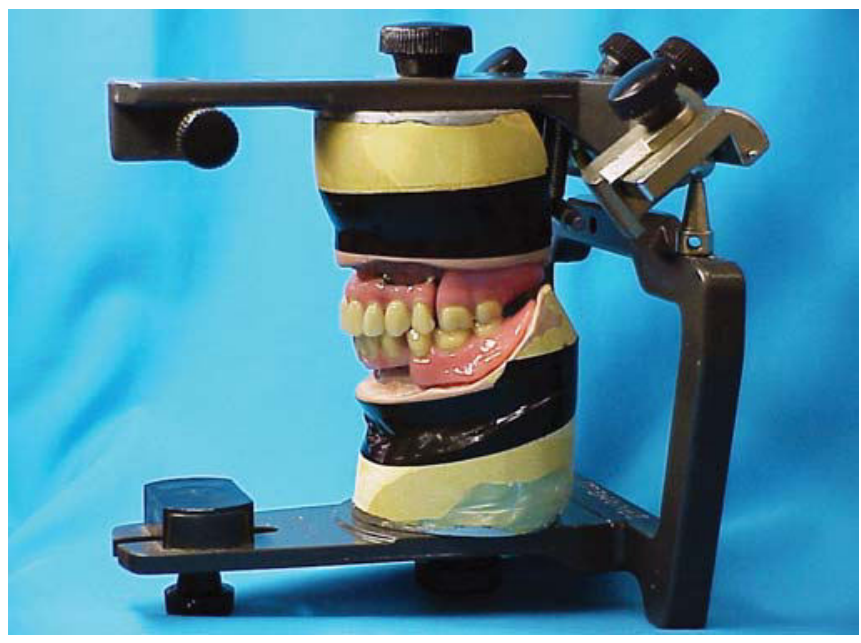

Fig. 1: Cast model mounted at semiadjustable articulator

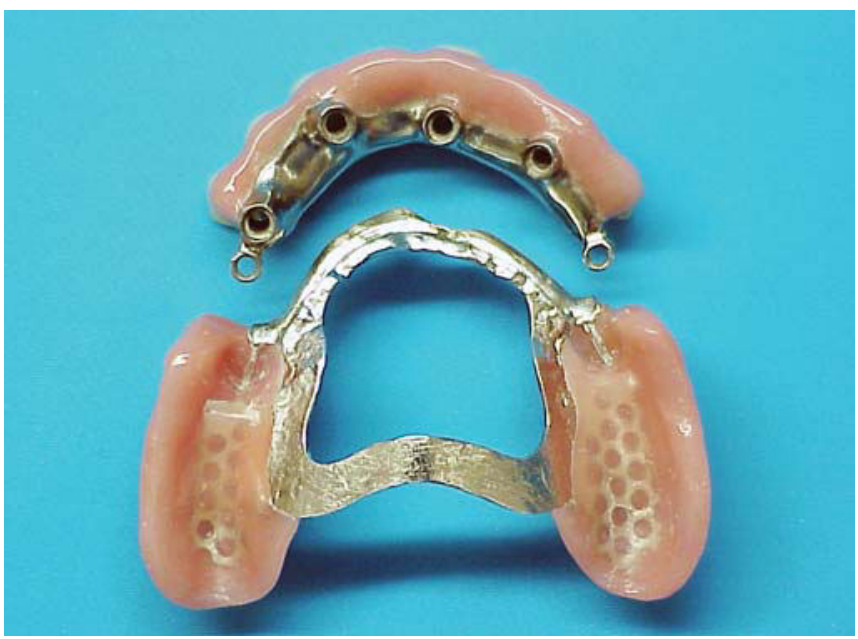

Fig. 2: Superior view of the maxilla prosthesis separate of the extra resilient attachment
4. Mount the maxillary definitive cast in a semiadjustable articulator using a face-bow record. Make a centric relation and mount the mandibular definitive cast in the articulator.

5. Wax-up and mount the superior and inferior teeth and make an impression putty index. This index is used to guide the dental technician when he is waxing the infrastructure.

6. Functional prove of the teeth verifying occlusion and esthetics.

7. Constructed the infrastructure with wax using UCLA abutments and verifying the adequate space with the index to the esthetics. Align and attach with a wax and using a surveyor, a castable ERA attachment.

8. Sprue, invest, cast, fit and polishes the infrastructure (obtained with titanium casting procedure) and fits onto the top of the implants. Prove this framework in the mouth to verify the framework adaptation.

9. Duplicate the definitive cast with the superstructure in position to obtain the removable framework. Wax the

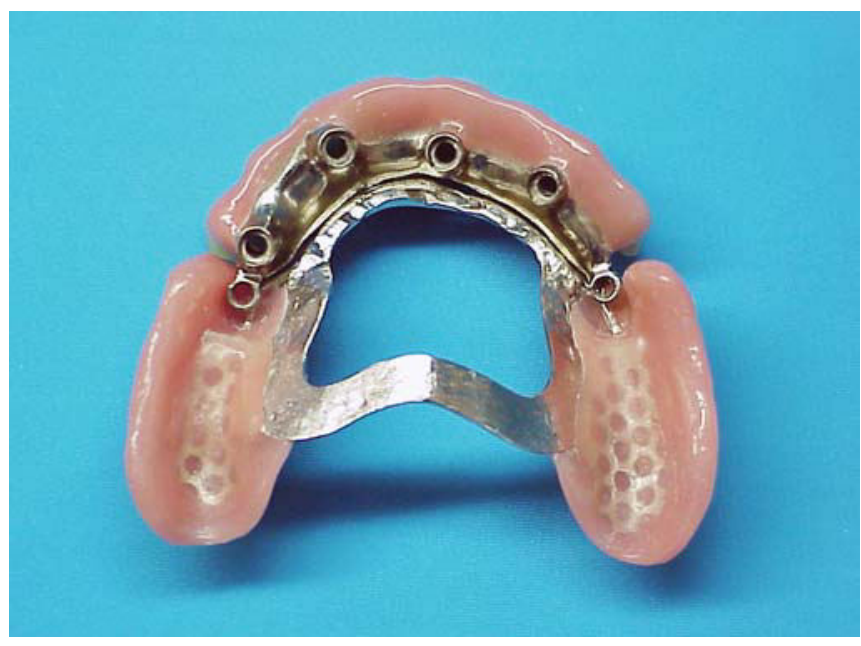

Fig. 3: Superior view of the maxilla prosthesis together with the extra resilient attachment

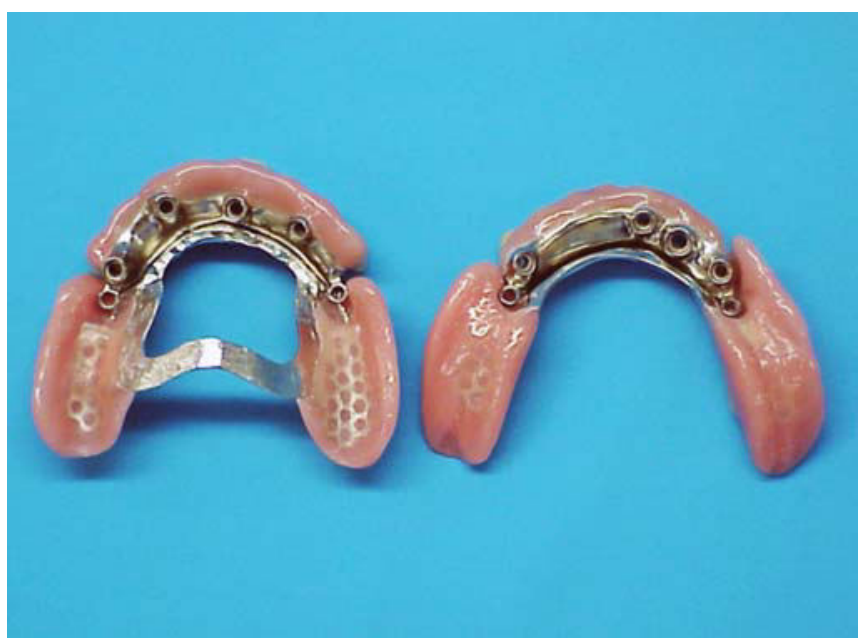

Fig. 4: Aspect of both prosthesis 
removable partial framework on the refractory cast, then sprue, invest, cast, fit and polish it.

10. Use the index and waxed the anterior superior and inferior segment as a guide to stack the artificial teeth

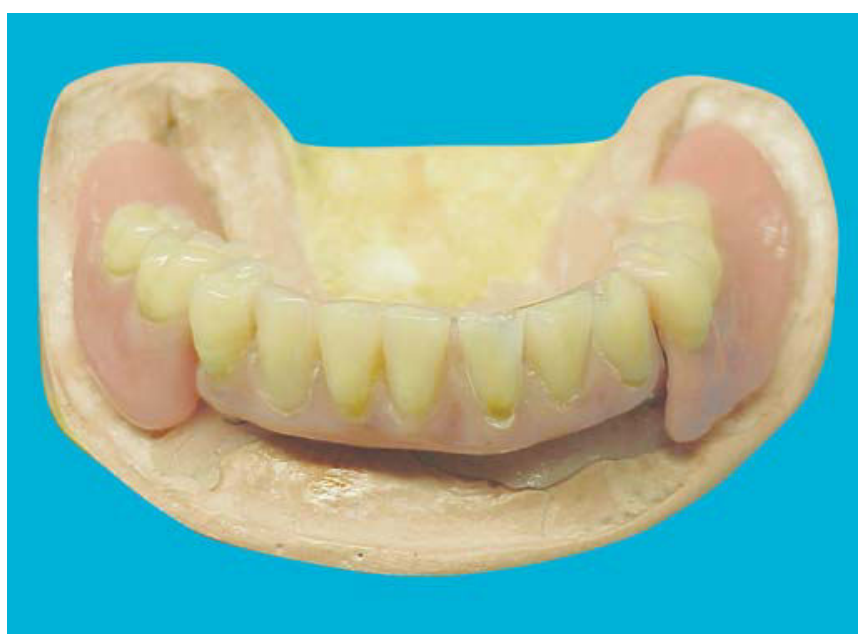

Fig. 5: Occlusal aspect of the anterior implant-fixed prosthesis with the removable partial denture in position

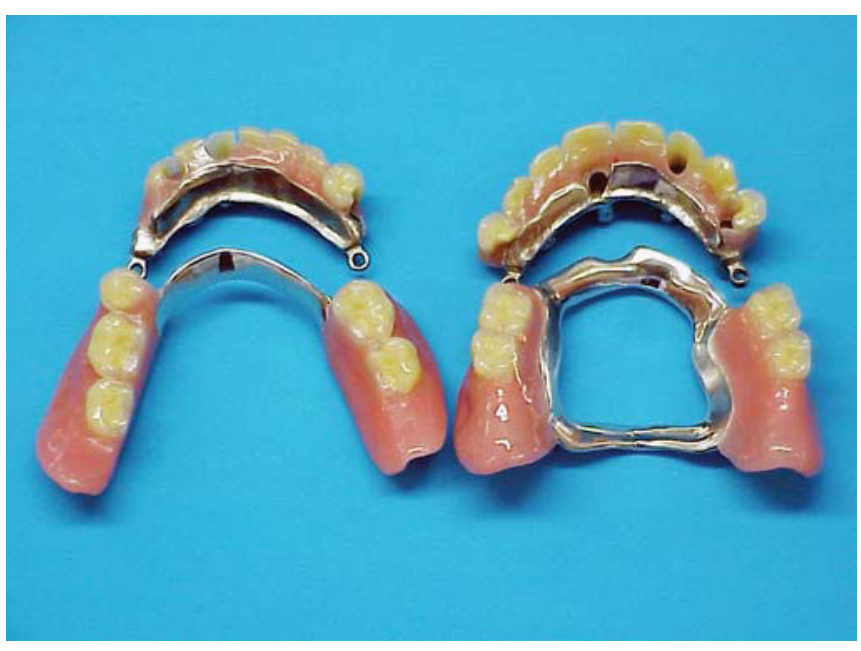

Fig. 6: Occlusal aspects of both prostheses

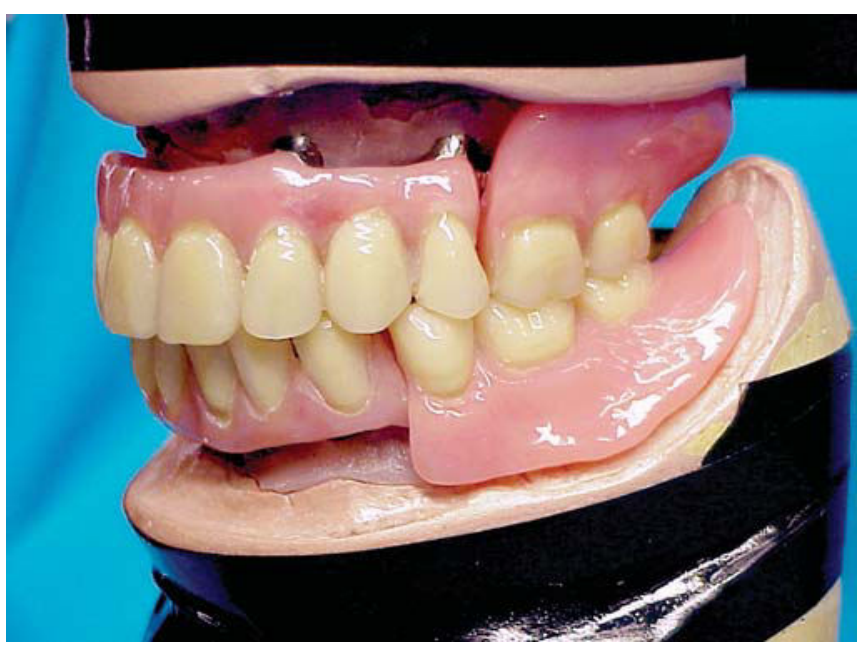

Fig. 7: Final aspect of both prostheses in the articulator position on the superstructure and develop the desired anatomy.

11. Reseat the maxillary and mandibular cast in the articulator and set the posterior teeth on the removable partial framework. Complete the wax-up for processing and invest, boil out, pack, process, recover and finish the removable partial denture.

12. Placed the anterior implant segment, fit the removable partial denture in the mouth and carefully adjust the occlusion. Placed the patrix pattern attachment in the matrix, set acrylic resin in the site of the removable denture attachment and maintain in occlusion still set. After set, remove the excess, polish and orientate the patient. Schedule follow-up visits of the patient.

\section{DISCUSSION}

Implant restorations for edentulous patients may be planned as either fixed restorations, removable overdentures or combining anterior fixed segment with removable partial denture with resilient attachment. ${ }^{5}$ Several factors should be considered when deciding between these treatment alternatives. They may grouped into factors related to: (a) the entire patient (preference, oral hygiene, medically debilitated, treatment complexities, economics), (b) both arches (bone presence, jaw relationship, previously placed hydroxyapatite, cantilever, interarch space, speech, congenital and acquired defects), (c) maxillary restorations (cantilever, excessive gag reflex, esthetics) and (d) mandibular restorations (denture-bearing mandible, knifeedge ridge, esthetics).$^{5}$

The alternative option of prosthetic treatment used in this study provides an emotional component for some patients who presents anatomical limitations and do not like that their teeth are removable. This kind of prosthesis reestablished adequate support for the soft tissues. In addition, an improvement in chewing efficiency and function is observed. ${ }^{3}$

The use of extracoronal resilient attachment need a minimum of $4 \mathrm{~mm}$ of vertical height and the measurement should be made on the crest from the gingival papillae to the marginal ridge on the abutment tooth. ${ }^{6}$ Measuring the axial wall of the tooth preparation of the working cast give an inaccurate measurement. In this case report, it was used the ERA castable resilient attachment (SterngoldImplamed), and must be positioned far enough from the soft tissue for oral hygiene access and have enough clearance occlusally for the attachment and the supporting removable partial denture.

The advantage of removable partial denture replacement is that some of the occlusal loading is placed on the soft tissue, thus reducing the occlusal loading for the implants. In addition, the potential for stress patterns in distal-extension 
removable partial denture retained by ERA extracoronal attachment with vertical resiliency suggest the use of supporting rest and abutment splitting, used in this case. ${ }^{7,8}$

\section{CONCLUSION}

This clinical report demonstrates the possibility of achieving positive results with a removable prosthesis with resilient attachment connected to an implant-supported fixed prosthesis when posterior anatomical limitations are present.

\section{REFERENCES}

1. Becker CM, Kaiser DA. Implant-retained cantilever fixed prosthesis: Where and when? J Prosthet Dent 2000;84:432-35.

2. Skalak R. Biomechanical consideration in osseointegrated prostheses. J Prosthet Dent 1983;49:843-48.

3. Pellecchia M, Pellecchia R, Emtiaz S. Distal extension mandibular removable partial denture connected to an anterior fixed implant-supported prosthesis: A clinical report. J Prosthet Dent 2000;83:607-12.

4. Zavanelli RA, Mesquita MF, Zavanelli AC. Reembasamento direto com material resiliente. Considerações e relato de caso clínico. Rev Bras Protese Clin Lab 2002;4:503-07.

5. Deboer J. Edentulous implants: Overdenture versus fixed. J Prosthet Dent 1993;69:388-90.

6. Williamson RT. Removable partial denture fabrication using extracoronal resilient attachments: A clinical report. J Prosthet Dent 1993;70:285-87.

7. Berg T, Caputo AA. Load transfer by a maxillary distalextension removable partial denture with cap and ring extracoronal attachments. J Prosthet Dent 1992;68:784-89.

8. Berg T, Caputo AA. Maxillary distal-extension removable partial denture abutments with reduced periodontal support. J Prosthet Dent 1993;70:245-50.

\section{ABOUT THE AUTHORS}

\section{Ricardo Alexandre Zavanelli (Corresponding Author)}

Associate Professor, Department of Prevention and Oral Rehabilitation, Federal University of Goias College and Dentistry Goiás/GO, Brazil, e-mail: ricardozavanelli@hotmail.com

\section{José Vitor Quinelli Mazaro}

Assistant Professor, Department of Dental Material and Prosthodontics FOA-UNESP, São Paulo, Brazil

\section{Adèrico Santana Guilherme}

Associate Professor, Department of Prevention and Oral Rehabilitation, FO-UFG, Goiás/Go, Brazil

\section{Jaqueline Barbosa Magalhães}

Postgraduate Student, Department of Prevention and Oral Rehabilitation FO-UFG, Goiás/GO, Brazil

\section{Leandro de Carvalho Cardoso}

Assistant Professor, Department of Prevention and Oral Rehabilitation FO-UFG, Goiás/GO, Brazil

\section{Adriana Cristina Zavanelli}

Assistant Professor, Department of Dental Material and Prosthodontics FOA-UNESP, São Paulo, Brazil 